\title{
Role of Sample Processing Strategies at the European Union National Reference Laboratories (NRLs) Concerning the Analysis of Pesticide Residues
}

\author{
Hajeb, Parvaneh; Herrmann, Susan Strange; Poulsen, Mette Erecius
}

Published in:

Journal of Agricultural and Food Chemistry

Link to article, DOI:

10.1021/acs.jafc.7b00728

Publication date:

2017

Document Version

Peer reviewed version

Link back to DTU Orbit

Citation (APA):

Hajeb, P., Herrmann, S. S., \& Poulsen, M. E. (2017). Role of Sample Processing Strategies at the European Union National Reference Laboratories (NRLs) Concerning the Analysis of Pesticide Residues. Journal of Agricultural and Food Chemistry, 65(28), 5759-5767. https://doi.org/10.1021/acs.jafc.7b00728

\section{General rights}

Copyright and moral rights for the publications made accessible in the public portal are retained by the authors and/or other copyright owners and it is a condition of accessing publications that users recognise and abide by the legal requirements associated with these rights.

- Users may download and print one copy of any publication from the public portal for the purpose of private study or research.

- You may not further distribute the material or use it for any profit-making activity or commercial gain

- You may freely distribute the URL identifying the publication in the public portal 
1 Role of sample processing strategies at the European Union National

2 Reference Laboratories (EU-NRLs) concerning the analysis of pesticide residue

3 control

4

5 Parvaneh Hajeb*; Susan S. Herrmann; and Mette E. Poulsen,

6 National Food Institute, Technical University of Denmark, Mørkhøj Bygade 19, DK-

72860 Søborg, Denmark

$8 \quad{ }^{*}$ Corresponding author. Tel +4535887000

9 Email address: parha@food.dtu.dk (P. Hajeb)

10

11

12

13

14

15

16

17

18

19

20 
The guidance document SANTE 11945/2015 recommends that cereal samples be

23 milled to a particle size preferably smaller than $1 \mathrm{~mm}$ and that extensive heating of

24 the samples should be avoided. The aim of the present study was therefore to

25 investigate the differences in milling procedures, obtained particle size distributions

26 and the resulting pesticide residue recovery when cereal samples were milled at the

27 European Union National Reference Laboratories (EU-NRLs) with their routine

28 milling procedures. A total of 23 NRLs participated in the study. The oat and rye

29 samples milled by each NRL were sent to the European Union Reference

30 Laboratory on Cereals and Feedingstuff (EURL-CF) for the determination of the

31 particle size distribution and pesticide residue recovery. The results showed that the

32 NRLs used several different brands and types of mills. Large variations in the particle

33 size distributions and pesticides recoveries were observed even between samples

34 milled by the same type of mill. size, SANTE 11945/2015 


\section{INTRODUCTION}

Several factors can influence the extractability of pesticides from cereals, such as the physicochemical properties of the pesticide, its accumulation in the grain's inner or outer parts, the type of pesticide application, and the cereal type, among other factors ${ }^{1}$. Incurred pesticide residues are not always easily extracted because they might be enclosed in cells, starch, or fat particles or undergo strong interactions with matrix. To facilitate the extractability of analytes, it is common to homogenize/grind or mill the sample either by a standard procedure or to produce the smallest particles possible with the available equipment. This strategy is based on the assumption that as the particle size decreases, the efficiency of the extraction increases because the surface area accessible to the solvent increases with decreasing particle size. Therefore, thorough sample processing to obtain small and homogeneous particle size is of great importance in pesticide residue analysis and all other fields of quantitative analysis. Nevertheless, this parameter is not evaluated when laboratories participate in proficiency tests regarding pesticide residue analysis or when they perform recovery studies on spiked samples. Proficiency test materials are processed by the provider of the test. Our previous study (unpublished data) showed that the particle size of cereal flour affects the extraction efficiency of incurred pesticides. A better extraction efficiency was achieved with smaller particle size. The guidance document SANTE $11945 / 2015^{2}$ recommends that laboratories mill to a particle size preferably less than $1 \mathrm{~mm}$. However, the milling procedures used in pesticide laboratories vary, and the equipment for studying particle size distribution is often not available. We have therefore investigated the differences in milling procedures and determined the particle size distributions in cereal samples milled by the European Union National Reference Laboratories (EU-NRLs) using their routine milling procedures as well as the extractability of pesticide residues from these 
samples. By this study, we expected to shed light on the variation in the sample processing strategies employed at the EU-NRLs performing pesticide residue control analysis as well as to obtain further data on the relationship between the particle size and extraction efficiency.

\section{EXPERIMENTAL}

\section{Chemicals}

Pesticide standards (all with a purity $>96 \%$ ) were purchased from Dr. Ehrenstorfer (Augsburg, Germany). Acetonitrile (HPLC Grade S) was purchased from Rathburn Chemicals (Walkerburn, UK) and acetic acid and ammonium acetate were purchased from Merck (Darmstadt, Germany). Magnesium sulfate was purchased from J.T. Baker, Aventor Performance Materials B.V (Center Valley, PA 18034, USA), sodium chloride was from Merck \& Co. (Whitehouse Station, NJ, USA), sodium citrate dehydrate and sodium citrate sesquihydrate were from Sigma Aldrich Chemie GmbH (Taufkirchen, Germany) and the clean-up sorbent PSA was from Agilent Technologies (Santa Clara, CA 95051, USA). The pesticide standard stock solutions of $1 \mathrm{mg} / \mathrm{ml}$ were prepared in toluene and stored at $-18{ }^{\circ} \mathrm{C}$ in ampoules under an argon atmosphere. The standard mixtures of $10 \mu \mathrm{g} / \mathrm{ml}$ in acetonitrile were prepared from these stock solutions. The working solutions were prepared by the dilution of the standard mixtures with acetonitrile and finally matching them 1:1 with an extract of blank flour (not containing pesticide residues) to obtain a concentration range of $0.0003-0.333 \mu \mathrm{g} / \mathrm{ml}$. The extracts of cereal samples with no pesticide content obtained by the in-house standard extraction and clean-up procedure, described in Section 2.2, were used for matrix matching. 


\section{Sample and Analytical Methods}

The oat and rye used in this study were grains grown and sprayed in the field produced in connection with the production of proficiency test material for the two EUPTs; EUPT-C3 (oat) and -C4 (rye). The levels of the incurred pesticides in the oat and rye test material, determined with our in-house method involving milling with a 1 $\mathrm{mm}$ sieve size, extraction by the in-house QuEChERS method (see section 0) and analysis by LC-MS/MS and GC-MS/MS, are presented in Table 1. One-hundred grams of both oat and rye grain were sent to 23 NRLs located in different EU regions. The samples were milled by these NRLs, using their routine sample processing procedure for pesticide analysis in cereals, and sent back to us for further studies.

\section{Size Distribution Analysis}

The sample size distribution for each of the samples milled by the 23 NRLs was determined after arrival at the EURL using a vibratory sieve shaker (Retsch AS 200, Haan, Germany). The sieving parameters (sample size, sieve time and amplitude) were optimized using different sample sizes (50 and $100 \mathrm{~g})$, amplitudes (2-3 mm) and sieving times (10-20 min). The optimal sieving conditions, which produced the most efficient separation of the flour particles, were obtained when using a sample size of $50 \mathrm{~g}$ of flour, $20 \mathrm{~min}$ of sieving time and an amplitude of $2.5 \mathrm{~mm}$. The flour samples were separated into fractions according to sieve mesh sizes of $50 \mu \mathrm{m}$ to $4.8 \mathrm{~mm}$ (see number and sieve mesh seizes in Table 3).

To ease the comparison between particle size distributions, the relative particle size (RPS) of each milled sample was calculated using the following formula: 


$$
R P S=\sum_{i=1}^{n}(A S * S A)
$$

122 RPS: relative particle size

123 AS: average sieve mesh size (calculated as average between sieve $n$ and sieve $n-1$ )

124 SA: sample amount in sieve $\mathrm{n}(\mathrm{g})$

\section{Pesticide Extraction and Clean-Up Procedure}

127 The samples were extracted using our standard procedure for cereals (QuEChERS)

128 . In brief, $5.0 \mathrm{~g}$ of milled cereal was added to $10 \mathrm{ml}$ of cold water and immediately 129 extracted with $10 \mathrm{ml}$ of acetonitrile by shaking the tube for $1 \mathrm{~min}$ by hand. To optimize 130 the extraction, a ceramic homogenizer was used. Afterward, $4.0 \mathrm{~g}$ magnesium 131 sulfate, $1.0 \mathrm{~g}$ sodium chloride, $1.0 \mathrm{~g}$ sodium citrate dihydrate and $0.5 \mathrm{~g}$ sodium citrate 132 sesquihydrate were added. After $1 \mathrm{~min}$ of shaking by hand and centrifugation for 10 $133 \mathrm{~min}$ at $4300 \mathrm{~g}, 8 \mathrm{ml}$ of the supernatant was transferred to a clean tube and stored at $134-80^{\circ} \mathrm{C}$ for a minimum of $1 \mathrm{~h}$. The extract was then thawed and when still very cold, it 135 was centrifuged at $4300 \mathrm{~g}$ for $5 \mathrm{~min}$. Thereafter, $6 \mathrm{ml}$ of cold extract was mixed with $136150 \mathrm{mg}$ PSA and $900 \mathrm{mg}$ magnesium sulfate. After shaking for $30 \mathrm{~s}$ and 137 centrifugation for $5 \mathrm{~min}$ at $4300 \mathrm{~g}, 4 \mathrm{ml}$ of the extract was withdrawn and mixed with $13840 \mu \mathrm{l}$ of $5 \%$ formic acid solution. To determine the effect of shaking on the extraction 139 efficiency, a sample of rye test material milled with a centrifugal mill with a sieve size 140 of $1 \mathrm{~mm}$ was extracted by shaking for $1 \mathrm{~min}$ and 5 min using a mechanical shaker 
141 (2010 Geno/Grinder, SPEX SamplePrep, Stanmore, UK) and compared with manual shaking for $1 \mathrm{~min}$. This final extract was analyzed by GC-MS/MS and LC-MS/MS.

\section{Chromatographic Separation and Detection}

GC-MS/MS analysis was performed on a Quattro Micro Tandem GC-MS/MS (Waters, USA). The system consisted of a PAL-GC autosampler, an Agilent GC 6890N and a Quattro Micro Tandem mass spectrometer. The GC was equipped with a Gerstel PTV injector for large volumes, and $4 \mu \mathrm{l}$ was injected. The injector program started with an initial temperature of $30{ }^{\circ} \mathrm{C}$ for $0.8 \mathrm{~min}$ followed by a ramp of 480 ${ }^{\circ} \mathrm{C} / \mathrm{min}$ to $290{ }^{\circ} \mathrm{C}$, which was held for $2 \mathrm{~min}$. Finally, the temperature was raised 720 ${ }^{\circ} \mathrm{C} / \mathrm{min}$ to $330{ }^{\circ} \mathrm{C}$ to clean the injector. The $\mathrm{GC}$ oven program started with an initial temperature of $60^{\circ} \mathrm{C}$ held for $3 \mathrm{~min}$, followed by a ramp of $30^{\circ} \mathrm{C} / \mathrm{min}$ to $180^{\circ} \mathrm{C}$. This temperature was held for $0.8 \mathrm{~min}$ and following by a ramp of $5{ }^{\circ} \mathrm{C} / \mathrm{min}$ to $280{ }^{\circ} \mathrm{C}$, which was held for $3 \mathrm{~min}$. To clean the column, the temperature was raised $40^{\circ} \mathrm{C} / \mathrm{min}$ to $300^{\circ} \mathrm{C}$ for $10 \mathrm{~min}$ and $120^{\circ} \mathrm{C} / \mathrm{min}$ to $310^{\circ} \mathrm{C}$ for $1 \mathrm{~min}$. Chromatographic separation was performed on a RESTEK, Rxiß-5 ms, $30 \mathrm{~m}, 0.25 \mathrm{~mm}$ ID, $0.25 \mu \mathrm{m}$ df column with a constant flow of $1.3 \mathrm{ml} / \mathrm{min}$ of helium as the carrier gas. The temperatures of the transfer line and ion source were set at $250^{\circ} \mathrm{C}$ and $180^{\circ} \mathrm{C}$, respectively. The mass spectrometer was operated in the electronic ionization mode (El, $70 \mathrm{eV})$.

LC-MS/MS analysis was performed on a HP1100 liquid chromatograph (Agilent Technologies, Palo Alto, CA, USA) connected to a Micromass Quattro Ultima Triple Quadrupole Instrument. The injection volume was $10 \mu \mathrm{l}$. The chromatographic separation was performed on a Genesis C18 column, $100 \mathrm{~mm} \times 3 \mathrm{~mm}, 4 \mathrm{~m}$ pore size, (Gracevydac, Hengoed, UK). In front of the separation column was a Phenomenex SecurityGuard column, C18 ODS, $4 \mathrm{~mm} \times 2 \mathrm{~mm}$ (Cheshire, UK). 
Solvent A was ammonium acetate/acetic acid solution at a concentration of $20 \mathrm{mM}$ each. Solvent B was $95 \%$ methanol and $20 \mathrm{mM}$ of both ammonium acetate and acetic acid. The total flow rate of eluents $A$ and $B$ was $0.3 \mathrm{ml} / \mathrm{min}$. The initial gradient was $100 \% \mathrm{~A}$, which was decreased to $50 \% \mathrm{~A}$ after 2 min and $0 \% \mathrm{~A}$ after $20 \mathrm{~min}$. Solvent A was held at $0 \%$ until $24 \mathrm{~min}$. The total run time was $30 \mathrm{~min}$. Ionization was performed by electrospray ionization in positive ion mode $(E S I+)$. The capillary voltage was set to $1.0 \mathrm{kV}$. The source temperature was $120^{\circ} \mathrm{C}$ and the desolvation temperature was $350^{\circ} \mathrm{C}$. Nitrogen was used as the desolvation gas (flow $550 \mathrm{l} / \mathrm{h}$ ) and cone gas (flow $50 \mathrm{l} / \mathrm{h}$ ), and argon was used as the collision gas at a pressure of $1.7 \times$ $10^{-3}$ mbar.

Both the GC-MS/MS and the LC-MS/MS were operated in MRM mode to perform mass spectrometric quantifications of the pesticides. The employed MRM transitions, retention times and collision energies are listed in Table 2. Quantification was based on bracketing calibration curves of five matrix matched standard solutions covering the relevant concentration range. Oat and rye blank material milled with a sieve size of $1 \mathrm{~mm}$ was used for the preparation of matrix matched calibration solutions.

\section{RESULTS AND DISCUSSION}

In a previous study, we studied the effect of particle size on the extraction efficiency of pesticides (unpublished data). It was confirmed that there is a relationship between decreasing particle size and increasing efficiency with which incurred pesticide residues are extracted from different cereals (barley, oat, rye and wheat). To obtain an overview of the situation in EU laboratories, a survey on the milling equipment, procedures employed and the particle size distributions obtained was performed. A total of 23 NRLs participated in the survey. Various types of mills including centrifugal 
mills (6), knife mills (10), hammer mills (3) and universal horizontal mills (4) were used by the different NRLs.

Several NRLs participating in the study used common coffee grinders (knife mill) to mill the cereal grains and several reported that heat was produced during milling. The determination of the particle size distribution of the oat and rye samples milled by NRLs revealed large variations in the particle size distribution and thereby also the RPS (Tables 3 and 4). The RPS ranged from 24-129 for oat and 16-155 for rye (Tables 5 and 6). Generally, samples milled by hammer mills and knife mills were inhomogeneous, with more than $35 \%$ of the sample accounted for as particles larger than $0.7 \mathrm{~mm}$ (Figure $1 \mathrm{a}$ and $\mathrm{b}$ ), whereas samples milled by centrifugal mills (at 0.5 or $1.0 \mathrm{~mm}$ ) were more homogenous and mainly consisted of particles smaller than 0.7 $\mathrm{mm}$. The smallest relative particle size (RPS) values of 16 and 24 for rye and oat, respectively, were observed for two samples that were milled frozen by a centrifugal mill. The largest RPS values of 129 and 155 were produced by a knife mill and a hammer mill for oat and rye, respectively (Tables 5 and 6 ). However, large variations were observed in the RPS for samples milled using the same type of mill, especially for rye samples milled by universal horizontal mills. These variations may be due to differences in size, quality, and the brand of the mill as well as the milling procedure employed. As observed in Tables 5 and 6 , knife mills may result in either quite efficient milling with an RPS of 30 or relatively insufficient milling with an RPS of 141. When comparing the particle size distribution for oat and rye obtained when ground with the same mill, a bigger fraction of larger particles was observed for rye than for oat. This may be due to differences in the texture, fat and moisture content of the oat and rye grains (Figure $1 \mathrm{a}$ and $\mathrm{b}$ ).

Determination of the extractability/recovery of the incurred pesticide from the samples milled by the NRLs showed that recovery was generally higher in samples with 
217 smaller RPS (Table 5 and 6). Consequently, a higher recovery was generally

218 observed for samples milled by centrifuge mills with a sieve size of 0.5 or $1.0 \mathrm{~mm}$

219 than for samples milled by knife mills and hammer mills. The recovery ranged from

22071 to $108 \%$ for oat and from 75 to $119 \%$ for rye. The low extraction efficiency found

221 for some samples, in spite of relatively low RPS, may be related to factors other than

222 particle size, e.g., the degradation of the pesticides due to unfavorable handling,

223 storage and/or transportation conditions. However, the NRLs were instructed to store

224 grain and flour in a freezer, and stability tests of the corresponding EUPT test

225 materials did not show degradation of the pesticides during 4 weeks of storage at

226 room temperature.

227 The results for oat samples showed a clear relationship between decreasing particle 228 size and increasing extraction efficiency of pesticides (Figure 2a). The recovery obtained for the samples with the smallest particles was up to $40 \%$ higher than the recovery for the largest particles. Significant differences (t-test, $p<0.05)$ were observed between the seven oat samples with the smallest RPS and the seven samples with the largest RPS in terms of the recovery of carbendazim, chlorpyrifos, cyprodinil, fenpropimorph, fenvalerate, flusilazole, lambda-cyhalothrin and pyraclostrobin. For rye, the relationship was less clear. However, significant differences in recovery were also observed for rye samples between those with the smallest and largest RPS, i.e., carbendazim, chlorpyrifos-methyl, fenpropimorph, flutriafol, kresoxim-methyl and spiroxamine (Figure 3b). The results indicate that if the laboratories change their milling procedure to obtain an RPS of 20 instead of $120 / 150$, it may increase the overall extraction efficiency by more than $35 \%$. As mentioned, efficient milling resulting in a low RPS may be obtained with several types of mill; however, by using a centrifugal mill with a specific sieve size, it is possible to 
242 have the process under control and obtain a reproducible result without relying on the 243 visual judgment of the operator.

244 In accordance with our previous study (unpublished data), the present study shows 245 that that smaller particle sizes increase extraction efficiency. In most routine 246 laboratories, the homogeneity of a sample is probably based on a visual and 247 personal evaluation unless a mill equipped with a specific sieve size is used. Thus, 248 most pesticide residue laboratories do not know which particle size distribution they 249 obtain by their standard homogenization procedure. Differences in the milling 250 procedures may therefore contribute significantly to the variability in the results of the 251 samples of grain analyzed by the pesticide laboratories as part of the common EU as 252 well as their national pesticide control programs.

253 Several factors may influence the extraction efficiency of a pesticide, e.g., the heat 254 sensitivity or polarity of the compound ${ }^{4-8}$. Most of the NRLs, especially those employing knife mills or hammer mills, noticed heat produced during milling. Only one of the NRLs milled frozen grains. We would expect that the degree of milling would have an influence on the extraction efficiency of pesticides if these pesticides are evenly distributed in the grain, whereas it would be of less importance if the residues primarily occurred on the surface or outer layers of the grain. A significant physical difference between oat and rye is that oat kernels are firmly covered by the hulls, while rye is not covered to the same extent ${ }^{9}$. Thus, the oat grain is protected from any direct application of pesticides. Further, when the grains mature, i.e., are allowed to dry in the field, the evaporation of water will occur in the oat on the surface of the hulls, whereas in rye, it will occur on the surface of the grain itself. Consequently, the rye grain is exposed to direct application, and when water evaporates from the surface of the rye grain, pesticide residue may precipitate. Thus, if the pesticide residue present in rye grain is primarily associated with the outer parts, i.e., the bran 
268 of the grains, it could be a reason for the observed weaker correlation between a 269 higher extraction efficiency and lower particle sizes for rye. As oat is protected by the 270 hulls and the evaporation of water during maturation will occur on the hulls, the 271 pesticide residue in oat grain may therefore be more evenly distributed, and the 272 degree of milling will consequently be of more importance.

273 Thus, the present study showed good correlation between increased extraction 274 efficiency and decreasing particle size. It may be assumed that this correlation is 275 observed because the extraction itself is not sufficient and that small particles then 276 compensate for insufficient extraction time. Hepperle et al. ${ }^{1}$ found up to a $20 \%$ higher recovery of pesticides from pineapple by increasing the extraction time from 1 to 15 278 minutes. We consequently tested if using a mechanical shaker and/or extending the extraction time could overcome the differences in extraction efficiency due to particle size. No difference was observed when the mechanical shaker was used for 1 min or 5 min compared to $1 \mathrm{~min}$ with hand shaking using rye test material with incurred pesticides milled with a centrifugal mill with a sieve size of $1 \mathrm{~mm}$. Thus, the manual extraction used for this study was shown to be sufficient. We also studied whether poor recovery as a result of poor milling (large particles) could be compensated for by increasing the extraction time. The recovery from rye test material milled using a sieve size of $5 \mathrm{~mm}$ was not affected by increasing the extraction time from 1 to 5 minutes using the mechanical shaker. Thus, the present study shows that, using mechanical extraction, even for a longer time, will not compensate for the poor milling of cereal. This phenomenon, of course, is only valid if the manual shaking is performed effectively. Furthermore, ceramic homogenizers are important to obtain optimal extraction.

292 NRLs use different types of mill/homogenization equipment for the sample 293 processing of cereal grains, which result in very different particle size distributions. 
294 Generally, the lowest RPS was obtained when the sample had been milled by a 295 centrifugal mill at a specific mesh size $(0.5 \mathrm{~mm})$. By using this equipment, the 296 procedure was also under control and reproducible. Common knife mills in most cases produced very inhomogeneous samples with high RPS. A clear relationship between an increasing extraction efficiency of incurred pesticides and decreasing RPS was found for all pesticides in oat and for most pesticides in rye. It is expected that the difference between oat and rye is due to more evenly distributed pesticides in the oat kernel because it is protected against direct exposure to pesticides by its hull. It was also shown that using mechanical extraction, even for a longer time, will not compensate for the poor milling of cereal.

\section{ACKNOWLEDGEMENTS}

The current study was performed in the framework of the EU Reference Laboratory for pesticide residue in cereal and feedstuff financed by the European Commission. The authors also acknowledge the NRLs that participated in this study and Gitte Andersen for assistance in sample preparation.

\section{REFERENCES}

(1) Hepperle, J.; Dörk, D.; Barth, A.; Taşdelen, B.; Anastassiades, M. Studies to improve the extraction yields of incurred pesticide residues from crops using the QuEChERS method. J. AOAC Int. 2015, 98 (2), 450-463.

(2) European Union (EC). SANTE/11945/2015. Guidance document on analytical quality control and method validation procedures for pesticides residues analysis in food and feed. 
http://ec.europa.eu/food/plant/docs/plant_pesticides_mrl_guidelines_wrkdoc_1 1945_en.pdf (accessed May 1, 2016).

320

321

322

323

324

(3) Herrmann, S. S.; Poulsen, M. E. Clean-up of cereal extracts for gas chromatography-tandem quadrupole mass spectrometry pesticide residues analysis using primary secondary amine and C18. J. Chromatogr. A 2015, $1423,47-53$.

(4) Senneca, O.; Scherillo, F.; Nunziata, A. Thermal degradation of pesticides under oxidative conditions. J. Anal. Appl. Pyrolysis 2007, 80 (1), 61-76.

(5) Sharma, J.; Satya, S.; Kumar, V.; Tewary, D. K. Dissipation of pesticides during bread-making. Chem. Heal. Saf. 2005, 12 (1), 17-22.

(6) Uygun, U.; Koksel, H.; Atli, A. Residue levels of malathion and its metabolites and fenitrothion in post-harvest treated wheat during storage, milling and baking. Food Chem. 2005, 92 (4), 643-647.

(7) Linde, C. D. Physico-Chemical Properties and Environmental Fate of Pesticides; California, 1994.

(8) Robert Mestres, G. M. Deltamethrin: uses and environmental safety. Rev. Environ. Contam. Toxicol. 1992, 124, 1-18.

(9) P. Koehler, H. W. Chemistry of Cereal Grains. In Handbook on Sourdough Biotechnology; M. Gobbetti, M. G., Ed.; Springer Science+Business Media: New York, 2013; pp 11-15. 
342 Figure captions

343 Figure 1. Average particle size of a) oat and b) rye samples milled by NRLs using 344 different types of mills.

345

346 Figure 2. Average relative particle size (RPS) and average pesticide recovery (\%) for 347 the seven samples with the smallest, middle and largest RPS, a) oat and b) rye.

348 Differences are significant (t-test, $\mathrm{P}<0.05)$ for pesticides marked with *. 
Table 1. Levels of incurred pesticides $(\mathrm{mg} / \mathrm{kg})$ in the oat and rye test materials.

\begin{tabular}{lll}
\hline & \multicolumn{2}{l}{ Reference value $\mathbf{( m g / k g )}$} \\
\cline { 2 - 3 } Compound & Oat & Rye \\
\hline Azoxystrobin & 0.18 & 0.31 \\
Carbendazim & 0.44 & 1.12 \\
Chlorpyrifos & 1.05 & - \\
Chlorpyrifos-methyl & - & 0.09 \\
Cyproconazole & 1.01 & - \\
Cyprodinil & 0.07 & - \\
Deltamethrin & - & 0.06 \\
Fenbuconazole & 0.55 & - \\
Fenpropimorph & 0.16 & 2.06 \\
Fenvalerate & 0.10 & - \\
Fludioxonil & 0.11 & - \\
Fluquinconazole & - & 0.63 \\
Flusilazole & 0.81 & - \\
Flutriafol & - & 2.81 \\
Kresoxim-methyl & - & 0.42 \\
Lambda-cyhalothrin & 0.03 & 0.04 \\
Malathion & - & 0.09 \\
Metconazole & 0.56 & - \\
Pirimiphos-methyl & - & 0.05 \\
Pyraclostrobin & 0.82 & - \\
Spiroxamine & - & 1.15 \\
Tebuconazole & 1.79 & - \\
Triadimenol & - & 1.83 \\
\hline & &
\end{tabular}


Table 2: Quantifier ions, qualifier transitions and collision energies for the GC-MS/MS and LC-MS/MS amenable pesticides included in the oat and rye test materials.

\begin{tabular}{|c|c|c|c|c|c|c|c|c|}
\hline & Pesticide & $\begin{array}{l}\text { Retention } \\
\text { time }\end{array}$ & $\begin{array}{l}\text { Precursor } \\
\text { ion-1 }\end{array}$ & $\begin{array}{l}\text { Product } \\
\text { ion-1 }\end{array}$ & $\begin{array}{l}\text { Collisions } \\
\text { energy } 1(\mathrm{~V})\end{array}$ & $\begin{array}{l}\text { Precurso } \\
r \text { ion-2 }\end{array}$ & $\begin{array}{l}\text { Product } \\
\text { ion-2 }\end{array}$ & $\begin{array}{l}\text { Collision } \\
\text { energy } 2 \\
\text { (V) }\end{array}$ \\
\hline \multirow{15}{*}{$\sum_{\substack{\infty \\
\bigcup_{0}^{\infty}}}^{\infty}$} & Azoxystrobin & 15.83 & 344 & 329 & 15 & 388 & 345 & 15 \\
\hline & Chlorpyrifos & 14.12 & 197 & 169 & 10 & 314 & 258 & 12 \\
\hline & Chlorpyrifos-methyl & 12.98 & 286 & 93 & 20 & 125 & 79 & 5 \\
\hline & Cyprodinil & 20.11 & 226 & 225 & 15 & 223 & 208 & 15 \\
\hline & Deltamethrin-cis & 29.29 & 181 & 152 & 10 & 253 & 174 & 10 \\
\hline & Fenbuconazole & 25.70 & 198 & 129 & 10 & 129 & 102 & 15 \\
\hline & Fenpropimorph & 14.27 & 303 & 128 & 5 & 117 & 115 & 10 \\
\hline & Fenvalerate & 14.07 & 167 & 125 & 10 & 125 & 99 & 10 \\
\hline & Kresoxim-methyl & 19.17 & 206 & 116 & 4 & 206 & 131 & 10 \\
\hline & Lambda-cyhalothrin & 22.26 & 197 & 141 & 10 & 208 & 181 & 10 \\
\hline & Malathion & 14.00 & 173 & 99 & 10 & 173 & 127 & 5 \\
\hline & Metconazole & 21.85 & 125 & 89 & 10 & 127 & 89 & 10 \\
\hline & Pirimiphos-methyl & 20.47 & 305 & 290 & 10 & 290 & 233 & 10 \\
\hline & Tebuconazole & 20.08 & 250 & 125 & 15 & 125 & 89 & 10 \\
\hline & Triadimenol & 15.50 & 168 & 70 & 5 & 128 & 100 & 10 \\
\hline \multirow{7}{*}{$\sum_{\substack{\infty \\
j}}^{\sum_{j}^{\infty}}$} & Carbendazim & 10.03 & 192 & 160 & 20 & 192 & 30 & 29 \\
\hline & Cyprodinil & 20.11 & 226 & 93 & 33 & 226 & 77 & 40 \\
\hline & Flusilazole & 18.93 & 316.17 & 247 & 17 & 316.17 & 165 & 20 \\
\hline & Kresoxim-methyl & 19.26 & 314 & 116 & 30 & 314 & 131 & 20 \\
\hline & Pirimiphos-methyl & 20.51 & 306 & 164 & 20 & 306 & 108 & 20 \\
\hline & Pyraclostrobin & 20.23 & 388.15 & 194 & 11 & 388.15 & 163 & 25 \\
\hline & Spiroxamine & 18.00 & 298.26 & 144 & 20 & 298.26 & 100 & 30 \\
\hline
\end{tabular}


Table 3. Particle size distribution for oat samples milled by NRLs using different mills, presented by the number of grams collected in the individual sieves.

\begin{tabular}{llllllllll}
\hline $\begin{array}{l}\text { Sieve size } \\
\text { (mm) }\end{array}$ & $0.05-0.1$ & $0.1-0.15$ & $0.15-02$ & $0.2-0.25$ & $0.25-0.35$ & $0.35-0.5$ & $0.5-0.71$ & $0.71-2.8$ & $>2.8$ \\
\hline Centrifugal & 3.3 & 16.5 & 13.5 & 16.2 & 26.4 & 15.6 & 8.4 & 0.7 & 0.0 \\
Centrifugal & 0.3 & 9.5 & 8.5 & 19.2 & 10.2 & 9.6 & 14.3 & 29.4 & 0.0 \\
Centrifugal & 0.4 & 5.1 & 5.0 & 10.0 & 20.7 & 13.4 & 22.3 & 23.1 & 0.0 \\
Centrifugal & 1.2 & 15.5 & 20.7 & 23.5 & 30.1 & 7.9 & 0.7 & 0.4 & 0.0 \\
Centrifugal & 0.3 & 6.6 & 17.3 & 18.0 & 14.7 & 12.2 & 20.2 & 10.8 & 0.0 \\
Centrifugal & 0.4 & 6.0 & 6.5 & 17.2 & 13.0 & 13.0 & 19.5 & 24.6 & 0.0 \\
Knife & 0.5 & 4.3 & 7.8 & 18.4 & 8.0 & 9.3 & 14.3 & 38.1 & 0.0 \\
Knife & 0.0 & 1.8 & 9.4 & 22.7 & 8.6 & 7.2 & 12.7 & 37.3 & 0.0 \\
Knife & 1.2 & 13.5 & 11.2 & 11.9 & 9.0 & 10.7 & 19.1 & 23.2 & 0.0 \\
Knife & 0.0 & 3.9 & 6.1 & 11.4 & 18.0 & 7.6 & 13.0 & 39.7 & 2.8 \\
Knife & 0.0 & 3.5 & 5.5 & 13.8 & 28.7 & 16.7 & 22.3 & 9.4 & 0.0 \\
Knife & 0.4 & 3.1 & 3.6 & 14.0 & 31.9 & 13.7 & 20.0 & 12.9 & 0.0 \\
Knife & 0.5 & 5.2 & 4.2 & 11.7 & 25.8 & 11.8 & 15.5 & 26.9 & 0.0 \\
Knife & 1.1 & 4.4 & 3.0 & 4.9 & 6.5 & 8.5 & 11.7 & 59.1 & 2.8 \\
Knife & 0.0 & 0.0 & 10.4 & 6.0 & 14.0 & 10.4 & 10.6 & 47.8 & 2.0 \\
Knife & 0.3 & 6.0 & 7.4 & 17.6 & 15.6 & 11.4 & 17.9 & 23.6 & 0.0 \\
Hammer & 0.4 & 3.8 & 4.0 & 12.2 & 8.3 & 7.1 & 9.6 & 54.4 & 1.4 \\
Hammer & 0.3 & 4.0 & 11.4 & 5.1 & 7.5 & 5.7 & 7.1 & 58.9 & 1.5 \\
Horizontal & 0.0 & 4.5 & 17.1 & 23.9 & 14.6 & 19.6 & 20.0 & 0.5 & 0.0 \\
Horizontal & 0.2 & 4.6 & 4.4 & 15.4 & 30.6 & 15.0 & 14.0 & 15.6 & 0.0 \\
Horizontal & 0.4 & 6.2 & 11.0 & 17.9 & 11.9 & 13.8 & 18.3 & 21.1 & 0.0 \\
Horizontal & 0.2 & 2.8 & 3.3 & 5.0 & 18.0 & 7.4 & 11.4 & 52.3 & 0.0 \\
Unknown & 0.3 & 2.7 & 3.0 & 12.9 & 20.2 & 10.4 & 14.8 & 35.5 & 0.0 \\
\hline
\end{tabular}


Table 4. Particle size distribution for rye samples milled by NRLs using different mills, presented by the number of grams collected in the individual sieves.

\begin{tabular}{|c|c|c|c|c|c|c|c|c|c|c|}
\hline $\begin{array}{l}\text { Sieve size } \\
(\mathrm{mm})\end{array}$ & $<0.05$ & $0.05-0.1$ & $0.1-0.15$ & $0.15-02$ & $0.2-0.25$ & $0.25-0.35$ & $0.35-0.5$ & $0.5-0.71$ & $0.71-2.8$ & $>2.8$ \\
\hline Centrifugal & 0.9 & 9.4 & 13.8 & 8.8 & 8.7 & 14.6 & 17.6 & 18.9 & 8.3 & 0.0 \\
\hline Centrifugal & 3.5 & 10.4 & 13.5 & 8.1 & 6.9 & 12.5 & 14.6 & 17.0 & 13.6 & 0.0 \\
\hline Centrifugal & 0.7 & 7.0 & 10.3 & 5.2 & 5.7 & 10.1 & 13.8 & 23.2 & 23.8 & 0.0 \\
\hline Centrifugal & 10.3 & 25.7 & 21.9 & 12.8 & 10.9 & 12.4 & 6.4 & 0.1 & 0.0 & 0.0 \\
\hline Centrifugal & 0.4 & 7.9 & 10.6 & 10.4 & 11.0 & 15.4 & 18.7 & 18.7 & 6.6 & 0.0 \\
\hline Centrifugal & 0.4 & 4.4 & 7.3 & 5.5 & 6.9 & 10.8 & 15.9 & 30.0 & 19.6 & 0.0 \\
\hline Knife & 0.5 & 2.7 & 8.2 & 4.6 & 5.3 & 6.9 & 8.3 & 11.6 & 52.7 & 2.1 \\
\hline Knife & 0.3 & 8.8 & 19.1 & 10.4 & 11.2 & 13.4 & 14.8 & 15.1 & 7.4 & 0.0 \\
\hline Knife & 1.0 & 7.0 & 8.9 & 6.2 & 6.3 & 8.4 & 10.2 & 15.9 & 36.7 & 1.2 \\
\hline Knife & 0.3 & 5.3 & 10.7 & 8.4 & 12.1 & 9.5 & 8.4 & 10.2 & 34.9 & 0.0 \\
\hline Knife & 0.4 & 4.1 & 12.9 & 19.4 & 19.9 & 19.1 & 13.6 & 8.9 & 2.0 & 0.0 \\
\hline Knife & 0.9 & 6.0 & 4.8 & 4.1 & 3.8 & 8.4 & 11.2 & 17.9 & 42.4 & 0.0 \\
\hline Knife & 0.4 & 4.5 & 14.9 & 12.2 & 9.4 & 12.0 & 12.4 & 13.9 & 20.7 & 0.0 \\
\hline Knife & 0.3 & 2.5 & 2.5 & 1.6 & 2.0 & 3.5 & 4.4 & 7.3 & 75.5 & 0.0 \\
\hline Knife & 0.5 & 1.9 & 3.4 & 3.4 & 3.7 & 5.8 & 7.9 & 12.1 & 61.0 & 3.5 \\
\hline Hammer & 6.5 & 23.2 & 26.8 & 10.6 & 14.5 & 10.5 & 6.2 & 0.7 & 1.2 & 0.0 \\
\hline Hammer & 0.0 & 0.8 & 1.5 & 1.2 & 1.7 & 3.6 & 4.3 & 7.3 & 79.2 & 2.1 \\
\hline Hammer & 0.3 & 2.8 & 8.3 & 2.8 & 4.5 & 6.8 & 8.2 & 13.9 & 52.4 & 0.0 \\
\hline Horizontal & 0.5 & 5.1 & 11.5 & 13.7 & 12.0 & 10.3 & 10.2 & 13.2 & 24.3 & 0.0 \\
\hline Horizontal & 0.0 & 6.4 & 9.3 & 6.4 & 8.1 & 14.1 & 21.1 & 24.9 & 8.8 & 0.0 \\
\hline Horizontal & 0.9 & 4.7 & 5.5 & 3.7 & 4.2 & 7.7 & 11.9 & 22.9 & 39.1 & 0.0 \\
\hline Horizontal & 0.6 & 2.1 & 3.6 & 2.8 & 2.9 & 5.2 & 7.2 & 9.9 & 66.5 & 0.0 \\
\hline Unknown & 0.3 & 2.1 & 9.9 & 9.2 & 6.8 & 8.0 & 9.2 & 13.4 & 41.4 & 0.0 \\
\hline
\end{tabular}


Table 5. Relative particle size and pesticide recovery (\%) obtained for oat samples milled by NRLs using different mills.

\begin{tabular}{|c|c|c|c|c|c|c|c|c|c|c|c|c|c|}
\hline Mill type & $\begin{array}{l}\text { Rel. } \\
\text { particle } \\
\text { size }\end{array}$ & Azoxystrobin & Carbendazim & Chlorpyrifos & Cyprodinil & Fenbuconazole & Fenpropimorph & Fenvalerate & Flusilazole & $\begin{array}{l}\text { Lambda- } \\
\text { cyhalothrin }\end{array}$ & Metconazole & Pyraclostrobin & $\begin{array}{l}\text { Mean } \\
\text { recovery }\end{array}$ \\
\hline Centrifugal & 24.5 & 97 & 118 & 121 & 126 & 98 & 109 & 106 & 108 & 91 & 120 & 99 & 108 \\
\hline Centrifugal & 29.4 & 110 & 126 & 110 & 108 & 105 & 92 & 118 & 116 & 87 & 131 & 100 & 109 \\
\hline Horizontal & 34.8 & 106 & 107 & 120 & 116 & 103 & 106 & 118 & 103 & 96 & 117 & 99 & 108 \\
\hline Centrifugal & 48.8 & 98 & 119 & 89 & 106 & 98 & 80 & 100 & 108 & 85 & 108 & 96 & 99 \\
\hline Knife & 50.4 & 106 & 110 & 125 & 116 & 99 & 117 & 114 & 102 & 87 & 112 & 93 & 107 \\
\hline Knife & 54.5 & 98 & 114 & 96 & 93 & 96 & 72 & 102 & 105 & 86 & 113 & 93 & 97 \\
\hline Horizontal & 56.4 & 97 & 116 & 121 & 108 & 87 & 150 & 97 & 92 & 78 & 103 & 88 & 103 \\
\hline Horizontal & 64.4 & 97 & 123 & 102 & 111 & 91 & 102 & 99 & 108 & 83 & 117 & 88 & 102 \\
\hline Knife & 65.9 & 96 & 108 & 97 & 91 & 96 & 86 & 102 & 99 & 90 & 110 & 89 & 97 \\
\hline Knife & 67.9 & 103 & 117 & 88 & 86 & 105 & 90 & 104 & 104 & 89 & 112 & 92 & 99 \\
\hline Centrifugal & 69.8 & 103 & 112 & 99 & 103 & 101 & 96 & 105 & 105 & 85 & 112 & 92 & 101 \\
\hline Centrifugal & 70.3 & 81 & 110 & 63 & 63 & 81 & 50 & 82 & 97 & 65 & 103 & 85 & 80 \\
\hline Knife & 73.4 & 96 & 110 & 92 & 98 & 98 & 86 & 105 & 100 & 86 & 105 & 94 & 97 \\
\hline Centrifugal & 74.6 & 101 & 129 & 79 & 78 & 103 & 62 & 112 & 118 & 89 & 124 & 104 & 100 \\
\hline Unknown & 85.7 & 84 & 108 & 81 & 78 & 83 & 66 & 83 & 100 & 65 & 107 & 78 & 85 \\
\hline Knife & 85.8 & 106 & 108 & 94 & 101 & 106 & 85 & 117 & 102 & 106 & 111 & 93 & 103 \\
\hline Knife & 87.9 & 96 & 110 & 71 & 70 & 92 & 64 & 96 & 99 & 79 & 104 & 88 & 88 \\
\hline Knife & 100.9 & 110 & 107 & 88 & 86 & 105 & 66 & 108 & 97 & 92 & 105 & 101 & 97 \\
\hline Horizontal & 109.3 & 90 & 106 & 80 & 86 & 85 & 66 & 87 & 93 & 66 & 102 & 82 & 86 \\
\hline Knife & 109.8 & 69 & 101 & 65 & 68 & 63 & 60 & 59 & 87 & 65 & 98 & 62 & 72 \\
\hline Hammer & 116.2 & 84 & 116 & 64 & 60 & 84 & 53 & 105 & 105 & 61 & 108 & 83 & 84 \\
\hline Hammer & 121.5 & 101 & 105 & 79 & 75 & 101 & 70 & 95 & 101 & 80 & 109 & 94 & 92 \\
\hline Knife & 129.2 & 83 & 105 & 57 & 64 & 80 & 53 & 79 & 93 & 79 & 97 & 84 & 79 \\
\hline
\end{tabular}


Table 6. Relative particle size and pesticide recovery (\%) obtained for rye samples milled by NRLs using different mills.

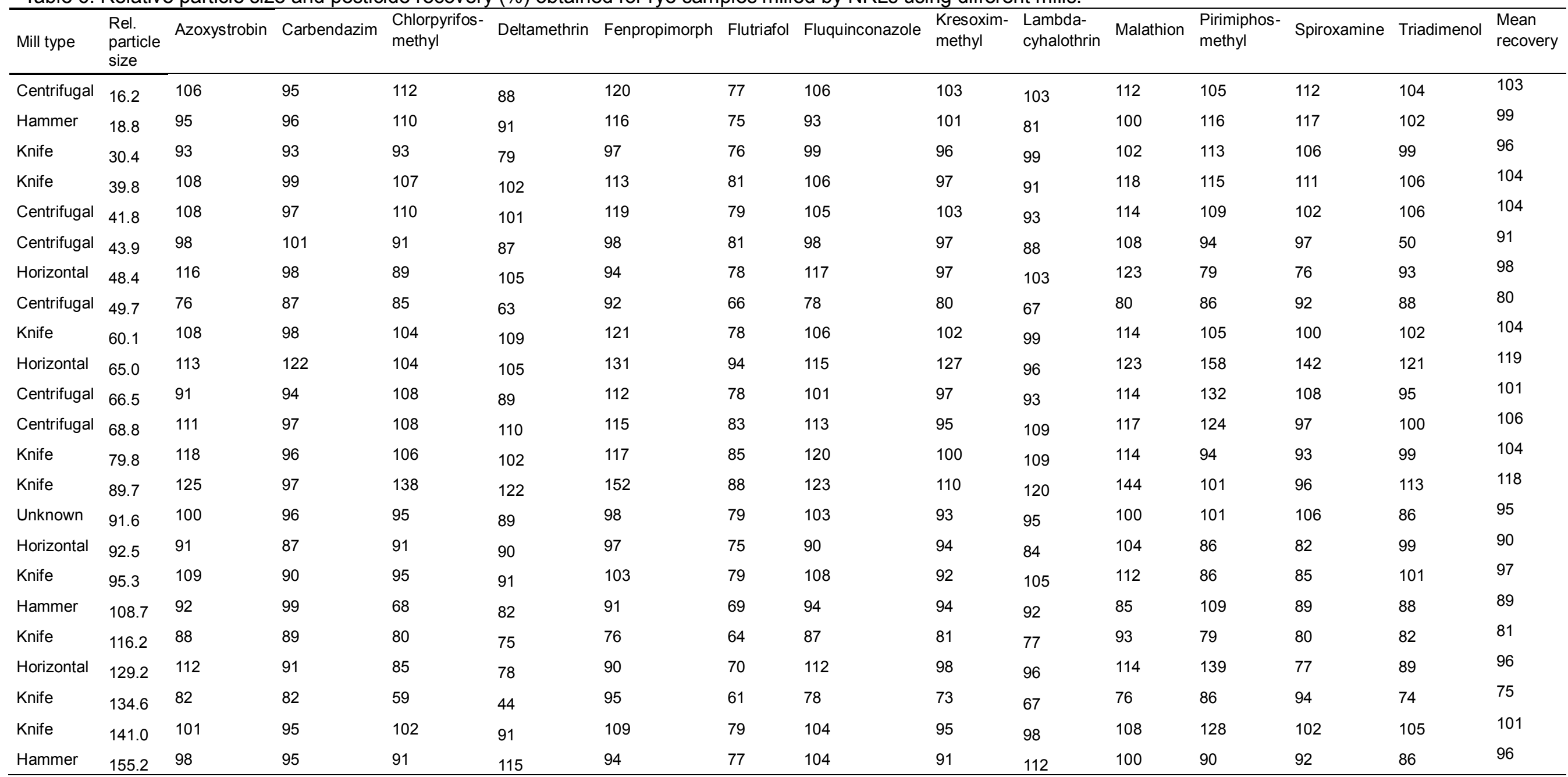




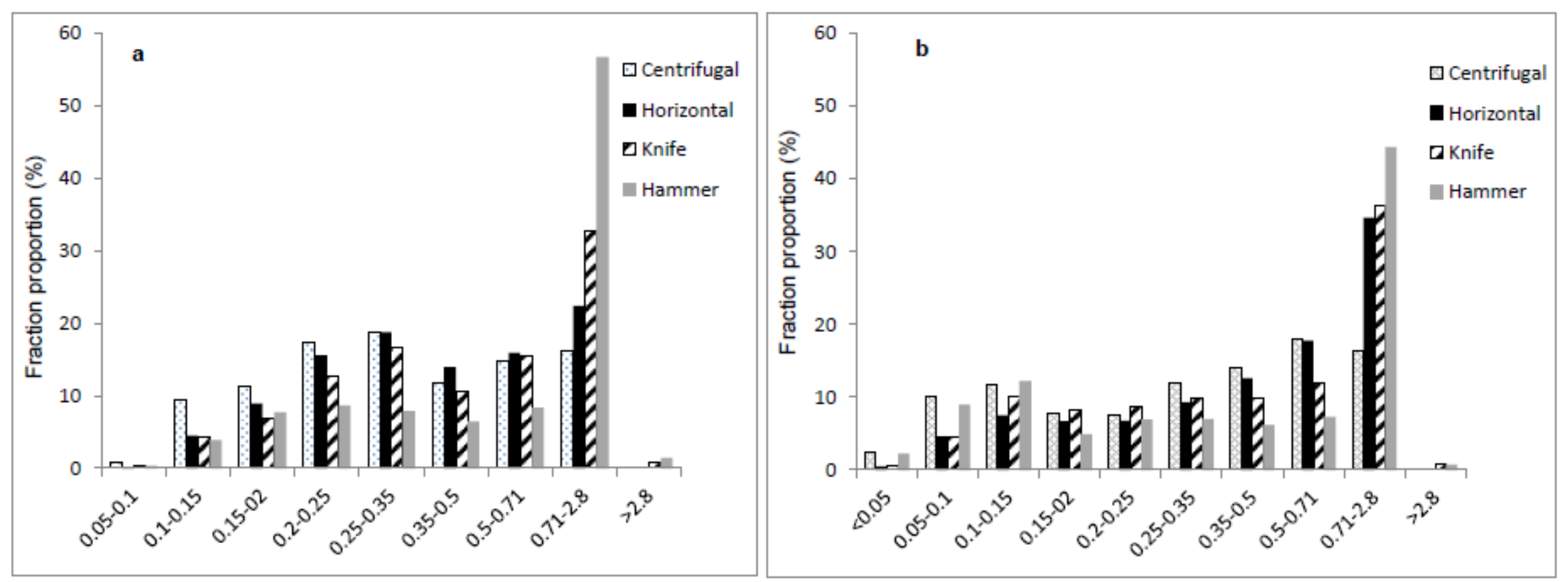

Figure 1. 

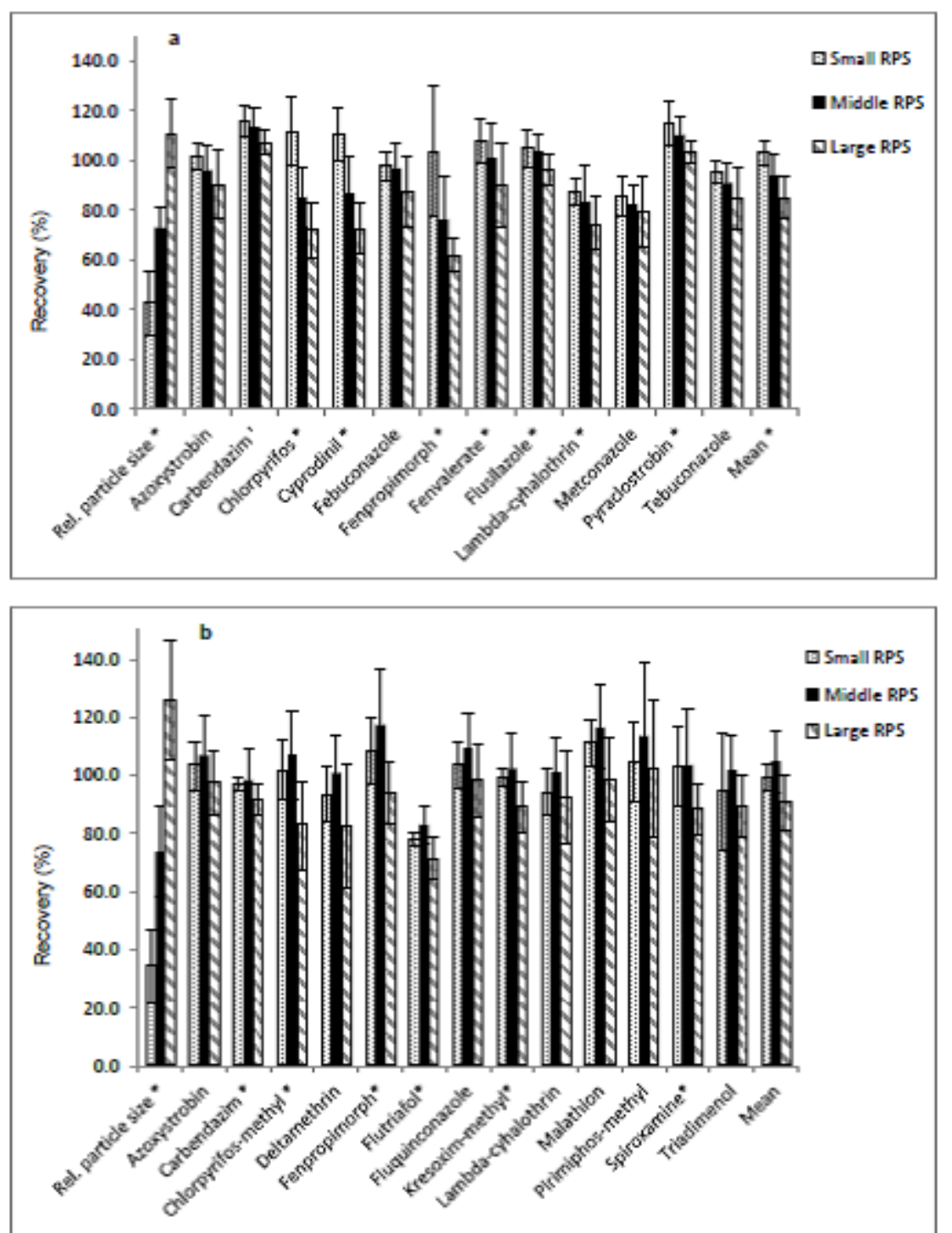

Figure 2. 
TOC Graphic

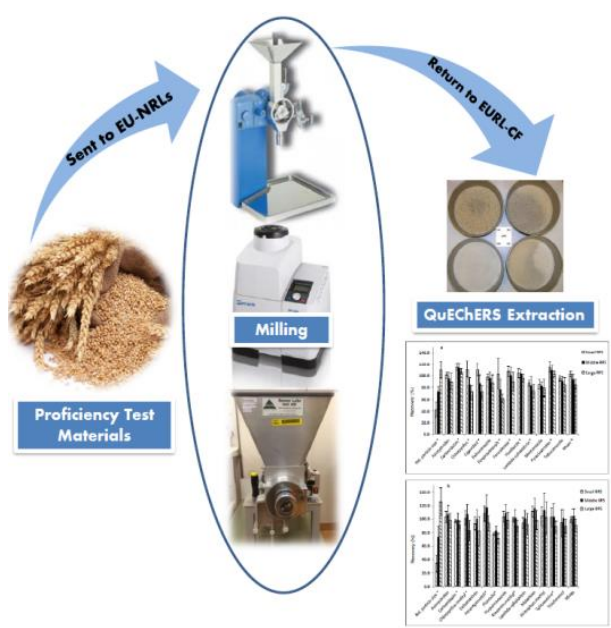

